Herz 2020 $45: 375-381$

https://doi.org/10.1007/s00059-018-4740-0

Received: 4 July 2018

Revised: 18 July 2018

Accepted: 28 July 2018

Published online: 27 November 2018

(c) The Author(s) 2018

CrossMark

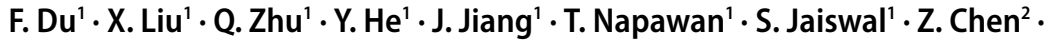

J. Wang'

'Department of Cardiology, Second Affiliated Hospital, Zhejiang University School of Medicine, Hangzhou, China

${ }^{2}$ Department of Clinical Epidemiology and Biostatistics, Second Affiliated Hospital, Zhejiang University School of Medicine, Hangzhou, China

\section{Sex-specific aortic root anatomy in patients with bicuspid aortic valve undergoing TAVR in a Chinese cohort}

\begin{tabular}{|c|c|c|c|c|}
\hline Variables & $\begin{array}{l}\text { Total } \\
(n=73)\end{array}$ & $\begin{array}{l}\text { Female } \\
(n=37)\end{array}$ & $\begin{array}{l}\text { Male } \\
(n=36)\end{array}$ & $p$ value \\
\hline \multicolumn{5}{|l|}{ Baseline characteristics } \\
\hline Age (year) & $74.30 \pm 6.15$ & $73.70 \pm 5.38$ & $74.92 \pm 6.87$ & 0.40 \\
\hline $\begin{array}{l}\text { Society of Thoracic Surgery risk of } \\
\text { mortality (\%) }\end{array}$ & $5.72 \pm 3.80$ & $5.83 \pm 4.39$ & $5.60 \pm 3.14$ & 0.47 \\
\hline Body mass index $\left(\mathrm{kg} / \mathrm{m}^{2}\right)$ & $22.66 \pm 3.03$ & $23.26 \pm 3.20$ & $22.04 \pm 2.76$ & 0.09 \\
\hline Body surface area $\left(\mathrm{m}^{2}\right)$ & $1.65 \pm 0.16$ & $1.6 \pm 0.1$ & $1.7 \pm 0.2$ & $<0.01$ \\
\hline Hypertension & $36(49.3 \%)$ & $16(43.2 \%)$ & $20(55.6 \%)$ & 0.29 \\
\hline Diabetes mellitus & $13(17.8 \%)$ & $5(13.5 \%)$ & $8(22.2 \%)$ & 0.33 \\
\hline Dyslipidemia & $25(34.2 \%)$ & $15(40.5 \%)$ & $10(27.8 \%)$ & 0.25 \\
\hline Prior MI & $1(1.4 \%)$ & $1(2.7 \%)$ & $0(0 \%)$ & 1.00 \\
\hline Prior $\mathrm{PCl}$ & $8(11.0 \%)$ & $3(8.1 \%)$ & $5(13.9 \%)$ & 0.68 \\
\hline Prior CABG & $0(0 \%)$ & $0(0 \%)$ & $0(0 \%)$ & - \\
\hline Prior stroke & $1(1.4 \%)$ & $0(0 \%)$ & $1(2.8 \%)$ & 0.49 \\
\hline Peripheral arterial disease & $14(19.2 \%)$ & $6(16.2 \%)$ & $8(22.2 \%)$ & 0.52 \\
\hline Atrial fibrillation/flutter & $15(20.5 \%)$ & $6(16.2 \%)$ & $9(25.0 \%)$ & 0.35 \\
\hline Prior pacemaker & $3(4.1 \%)$ & $2(5.4 \%)$ & $1(2.8 \%)$ & 1.00 \\
\hline NYHA & - & - & - & 0.53 \\
\hline NYHA II & $13(17.8 \%)$ & $6(16.2 \%)$ & $7(19.4 \%)$ & - \\
\hline NYHA III & $33(45.2 \%)$ & $15(40.5 \%)$ & $18(50.0 \%)$ & - \\
\hline NYHA IV & $27(37.0 \%)$ & $16(43.2 \%)$ & $11(30.6 \%)$ & - \\
\hline Chronic obstructive pulmonary disease & $15(20.5 \%)$ & $6(16.2 \%)$ & $9(25.0 \%)$ & 0.35 \\
\hline Dialysis & $1(1.4 \%)$ & $0(0 \%)$ & $1(2.8 \%)$ & 0.49 \\
\hline eGFR (ml/min) & $60.85 \pm 22.65$ & $63.02 \pm 24.32$ & $58.61 \pm 20.91$ & 0.41 \\
\hline \multicolumn{5}{|l|}{ Echocardiographic findings } \\
\hline Left ventricular ejection fraction (\%) & $53.80 \pm 14.53$ & $55.52 \pm 14.91$ & $52.03 \pm 14.11$ & 0.31 \\
\hline Aortic valve mean gradient $(\mathrm{mm} \mathrm{Hg})$ & $60.74 \pm 18.17$ & $63.92 \pm 18.88$ & $57.47 \pm 17.07$ & 0.13 \\
\hline Aortic valve maximum velocity $(\mathrm{m} / \mathrm{s})$ & $5.00 \pm 0.72$ & $5.15 \pm 0.70$ & $4.85 \pm 0.72$ & 0.08 \\
\hline Aortic valve area $\left(\mathrm{cm}^{2}\right)$ & $0.55 \pm 0.17$ & $0.54 \pm 0.19$ & $0.55 \pm 0.14$ & 0.79 \\
\hline
\end{tabular}

F. Du and X. Liu contributed equally to the manuscript.

\section{Electronic supplementary material}

The online version of this article (https://doi. org/10.1007/s00059-018-4740-0) contains supplementary material, which is available to authorized users.

\section{Introduction}

Transcatheter aortic valve replacement (TAVR) has become an alternative treatment for patients with symptomatic severe aortic valve stenosis (AS) who were deemed as inoperable with high or moderate risk for surgical aortic valve replacement [1]. Patients with a bicuspid aortic valve (BAV) often have concomitant aortopathy such as ascending aortic dilatation, aortic aneurysm and aortic dissection [2]. In China, patients presenting for TAVR have a very high proportion of BAV morphology and severe calcium burden compared with western TAVR registries [3]. BAV has been considered a relative contraindication to TAVR [4]. Recent studies suggest that TAVR appears to be a safe and effective procedure for BAV as well as the tricuspid aortic valve [5-7]. To select appropriate prosthesis size and avoid serious complications such as paravalvular leakage, 


\section{Original articles}

\begin{tabular}{|c|c|c|c|c|c|}
\hline Parameters & $\begin{array}{l}\text { Total } \\
(n=73)\end{array}$ & $\begin{array}{l}\text { Female } \\
(n=37)\end{array}$ & $\begin{array}{l}\text { Male } \\
(n=36)\end{array}$ & $p$ value & $\begin{array}{l}\text { General } \\
\text { linear } \\
\text { model } \\
p \text { value }\end{array}$ \\
\hline \multicolumn{6}{|l|}{ Annulus } \\
\hline Maximum diameter (mm) & $27.6 \pm 3.0$ & $25.8 \pm 2.1$ & $29.3 \pm 2.6$ & $<0.01$ & $<0.01$ \\
\hline Minimum diameter (mm) & $21.6 \pm 2.5$ & $20.7 \pm 1.9$ & $22.7 \pm 2.7$ & $<0.01$ & 0.01 \\
\hline Mean diameter $(\mathrm{mm})$ & $24.7 \pm 2.4$ & $23.4 \pm 1.8$ & $26.1 \pm 2.1$ & $<0.01$ & $<0.01$ \\
\hline Area $\left(\mathrm{mm}^{2}\right)$ & $475.7 \pm 88.8$ & $425.3 \pm 59.4$ & $527.4 \pm 84.6$ & $<0.01$ & $<0.01$ \\
\hline Area-derived diameter (mm) & $24.5 \pm 2.2$ & $23.2 \pm 1.6$ & $25.8 \pm 2.1$ & $<0.01$ & $<0.01$ \\
\hline Perimeter (mm) & $78.7 \pm 7.3$ & $74.3 \pm 5.2$ & $83.2 \pm 6.4$ & $<0.01$ & $<0.01$ \\
\hline $\begin{array}{l}\text { Perimeter-derived diameter } \\
(\mathrm{mm})\end{array}$ & $25.0 \pm 2.3$ & $23.7 \pm 1.6$ & $26.5 \pm 2.1$ & $<0.01$ & $<0.01$ \\
\hline \multicolumn{6}{|l|}{ STJ } \\
\hline Diameter (mm) & $31.1 \pm 4.1$ & $29.7 \pm 3.1$ & $32.6 \pm 4.5$ & 0.003 & 0.01 \\
\hline Height (mm) & $23.7 \pm 4.7$ & $22.7 \pm 3.9$ & $24.7 \pm 5.2$ & 0.070 & 0.13 \\
\hline \multicolumn{6}{|l|}{ Ascending aorta } \\
\hline Maximum diameter (mm) & $43.0 \pm 4.5$ & $41.9 \pm 4.4$ & $44.2 \pm 4.4$ & 0.032 & 0.14 \\
\hline Diameter $(4 \mathrm{~cm})(\mathrm{mm})$ & $39.3 \pm 4.1$ & $38.4 \pm 3.9$ & $40.3 \pm 4.1$ & 0.040 & 0.23 \\
\hline LM height (mm) & $16.3 \pm 3.7$ & $15.6 \pm 2.9$ & $17.0 \pm 4.2$ & 0.087 & 0.12 \\
\hline RCA height (mm) & $16.7 \pm 3.1$ & $15.9 \pm 2.4$ & $17.6 \pm 3.6$ & 0.021 & 0.06 \\
\hline Aortic root angle $\left(^{\circ}\right)$ & $54.8 \pm 9.6$ & $54.4 \pm 10.1$ & $55.3 \pm 9.1$ & 0.700 & 0.91 \\
\hline Aortic root calcification & - & - & - & 0.210 & - \\
\hline Mild & $4(5.5 \%)$ & $3(8.1 \%)$ & $1(2.8 \%)$ & - & - \\
\hline Moderate & $11(15.1 \%)$ & $8(21.6 \%)$ & $3(8.3 \%)$ & - & - \\
\hline Severe & $26(35.6 \%)$ & $13(35.1 \%)$ & $13(36.1 \%)$ & - & - \\
\hline Massive & $32(43.8 \%)$ & $13(35.1 \%)$ & $19(52.8 \%)$ & - & - \\
\hline
\end{tabular}

plane (defined as the plane perpendicular to the long axis of the aortic centerline). We measured the parameters of the annulus plane including maximum diameter, minimum diameter, mean diameter, area and perimeter, area-derived diameter and perimeter-derived diameter were calculated. For the STJ plane, STJ height and average diameter were measured. Coronary height was defined as the distances between the annulus plane and the lower border of the coronary ostia. The maximum diameter and diameter of ascending aorta $4 \mathrm{~cm}$ above the annulus plane were measured. The aortic valve calcification degree and aortic root angle were also evaluated. Complications and clinical endpoints were defined according to Valve Academic Research Consortium (VARC) 2 criteria [17]. This study was approved by the institutional review board and carried out according to the principles of the Declaration of Helsinki.

\section{Statistical analysis}

Continuous variables were expressed as mean \pm standard deviation (SD). The baseline characteristics of the patients in this study, stratified by sex, were compared using Student $t$ test or Man$\mathrm{n}$-Whitney test for continuous variables. The chi-square $\left(\chi^{2}\right)$ test was used for categorical variables. A generalized liner model was used to define the effect of body surface area (BSA) on the studied parameters. In the analysis of covariance, a $P$ value $<0.05$ was defined as statistically significant; also in the other tests the $P$ value $<0.05$ was defined as statistically significant. Statistical analysis was performed with a statistical software package (SPSS, version 19.0, IBM Armonk, NY, USA).

\section{Results}

\section{Baseline characteristics and CT aortic root data}

A total of 73 patients with bicuspid AS were treated with TAVR in the Second Affiliated Hospital of Zhejiang University between July 2013 and April 2017. Baseline characteristics of the 
Herz 2020 - 45:375-381 https://doi.org/10.1007/s00059-018-4740-0

(c) The Author(s) 2018

F. Du · X. Liu · Q. Zhu · Y. He · J. Jiang · T. Napawan · S. Jaiswal · Z. Chen · J. Wang

\section{Sex-specific aortic root anatomy in patients with bicuspid aortic valve undergoing TAVR in a Chinese cohort}

\section{Abstract}

Objectives. The aim of this study is to investigate the sex-specific aortic root anatomy in patients with bicuspid aortic valve (BAV).

Patients and methods. This retrospective study includes 73 consecutive patients with BAV who underwent CT evaluation before transcatheter aortic valve replacement (TAVR) between July 2013 and April 2017 in the Second Affiliated Hospital of Zhejiang University.

Result. The size of the annulus, diameter and height of the sinotubular junction (STJ), height of the coronary artery ostia, and dimension of the aorta were measured. Women had significantly smaller annulus parameters (mean diameter: $23.4 \pm 1.8$ vs. $26.1 \pm 2.1$ $\mathrm{mm}$; area: $425.3 \pm 59.4$ vs. $527.4 \pm 84.6 \mathrm{~mm}^{2}$; perimeter: $74.3 \pm 5.2$ vs. $83.2 \pm 6.4 \mathrm{~mm}$ ), and STJ diameter $(29.7 \pm 3.1$ vs. $32.6 \pm 4.5$ $\mathrm{mm}$ ) than men ( $p<0.01$ for all), even after adjustment for their smaller body surface area (BSA). Dimension of aorta and height of right coronary artery were also significantly smaller in women, although not when indexing for the BSA. The left ventricular ejection fraction of women is significantly higher than that of men before discharge $(60.2 \pm 9.7 \%$ vs. $53.7 \pm 13.6 \%, p=0.01$ ). There were no differences between women and men in the all-cause 30-day and 1-year mortality. Conclusion. Women with BAV had smaller annulus and STJ diameter after indexing for $B S A$, reflecting a sex-specific difference. There were no differences in 30-day and 1-year mortality between the two groups.

\section{Keywords}

Transcatheter aortic valve replacement · Sex ratio - Aortic root - Computed tomography . Aortic valve stenosis

\section{Geschlechtsspezifische Anatomie der Aortenwurzel bei Patienten mit bikuspidaler Aortenklappe und kathetergestützter Aortenklappenimplantation in einer chinesischen Kohorte}

\section{Zusammenfassung}

Zielsetzung. Ziel der vorliegenden Studie war es, die geschlechtsspezifische Anatomie der Aortenwurzel bei Patienten mit bikuspidaler Aortenklappe (BAK) zu untersuchen.

Patienten und Methoden. In die retrospektive Studie wurden 73 konsekutive Patienten mit BAK eingeschlossen, die sich zwischen Juli 2013 und April 2017 im Second Affiliated Hospital of Zhejiang University einer CTUntersuchung vor kathetergestützter Aortenklappenimplantation („transcatheter aortic valve replacement ${ }^{\prime \prime}$ [TAVR]) unterzogen hatten.

Ergebnisse. Die Größe des Anulus, der Durchmesser und die Höhe des sinutubulären Übergangs (STÜ), die Höhe der Koronarostien und die Dimension der Aorta wurden gemessen. Frauen hatten signifikant kleinere Anulusparameter (mittlerer Durchmesser: $23,4 \pm 1,8$ vs. $26,1 \pm 2,1 \mathrm{~mm}$; Fläche: $425,3 \pm 59,4$ vs. $527,4 \pm 84,6 \mathrm{~mm}^{2}$; Umfang: $74,3 \pm 5,2$ vs. $83,2 \pm 6,4 \mathrm{~mm}$ ) und STÜDurchmesser $(29,7 \pm 3,1$ vs. $32,6 \pm 4,5 \mathrm{~mm})$ als Männer (jeweils $p<0,01$ ), auch nach Adjustierung für ihre kleinere Körperoberfläche (KOF). Die Dimension der Aorta und die Höhe der rechten Koronararterie waren ebenfalls bei Frauen signifikant kleiner, allerdings nicht bei Berücksichtigung der KOF. Die linksventrikuläre Ejektionsfraktion vor der Entlassung war bei Frauen signifikant höher als bei Männern $(60,2 \pm 9,7 \%$ vs. $53,7 \pm 13,6 \%$, $p=0,01)$. Bezüglich der 30-Tages- und 1-Jahres-Gesamtmortalität bestanden keine Unterschiede zwischen Männern und Frauen. Schlussfolgerung. Frauen mit BAK hatten einen kleineren Anulus und STÜ-Durchmesser nach Adjustierung für die KOF, worin sich ein geschlechtsspezifischer Unterschied zeigt. Bezüglich der 30-Tages- und 1-JahresMortalität bestanden keine Unterschiede zwischen den beiden Gruppen.

Schlüsselwörter

Kathetergestützte Aortenklappenimplantation - Geschlechtsverhältnis . Aortenwurzel · Computertomographie . Aortenklappenstenose study population (50.7\% women, $49.3 \%$ men) are summarized in $\bullet$ Table 1. There were no clinical differences including echocardiography data between men and women except that women had a smaller BSA compared to men $\left(1.6 \pm 0.1\right.$ vs. $\left.1.7 \pm 0.2 \mathrm{~m}^{2}, p<0.01\right)$. The parameters of aortic root measured by CT are displayed in • Table 2 and $\bullet$ Fig. 1. In the annulus plane, maximum diameter, minimum diameter, mean diameter, area, perimeter, area-derived diameter and perimeter-derived diameter were significantly smaller in women than in men $(p<0.01$ for all). The average diam- eter of the STJ was significantly smaller among women than men $(29.7 \pm 3.1$ vs. $32.6 \pm 4.5 \mathrm{~mm}, p=0.003)$; however, the height of the STJ was comparable among women and men $(22.7 \pm 3.9$ vs. $24.7 \pm 5.2 \mathrm{~mm}, p=0.070)$. The distance of the annulus plane to the right coronary ostia is smaller in women than in men $(15.9 \pm 2.4$ vs. $17.6 \pm 3.6 \mathrm{~mm}, p=0.021)$; there was no significant difference in the height of the left coronary ostia in both groups $(15.6 \pm 2.9$ vs. $17.0 \pm 4.2 \mathrm{~mm}$, $p=0.087)$. The maximum diameter and the diameter of the ascending aorta $4 \mathrm{~cm}$ above the annulus plane were signifi- cantly smaller among women than men ( $41.9 \pm 4.4$ vs. $44.2 \pm 4.4 \mathrm{~mm}, p=0.032$; $38.4 \pm 3.9$ vs. $40.3 \pm 4.1 \mathrm{~mm}, p=0.040$, respectively). There were no significant sex differences in the aortic root angle and aortic valve calcification degree.

\section{Analysis on the influence of BSA on aortic root}

In order to exclude the impact of the BSA on the anatomical structure parameters measured by $\mathrm{CT}$, we consider sex is an important independent variable and BSA as covariance, we found that women have 

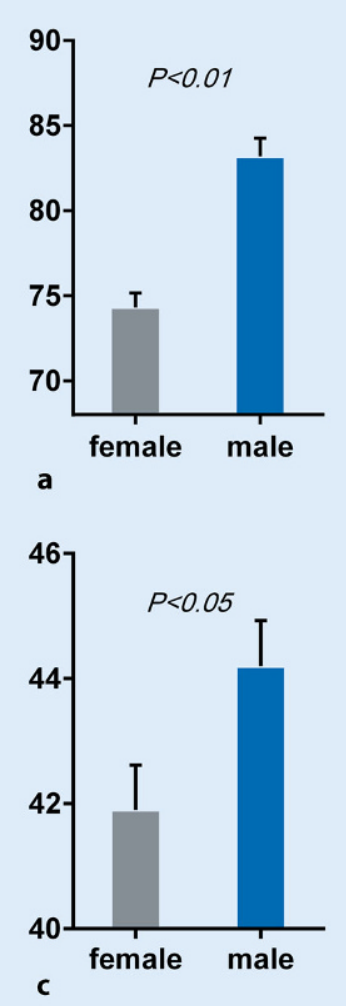
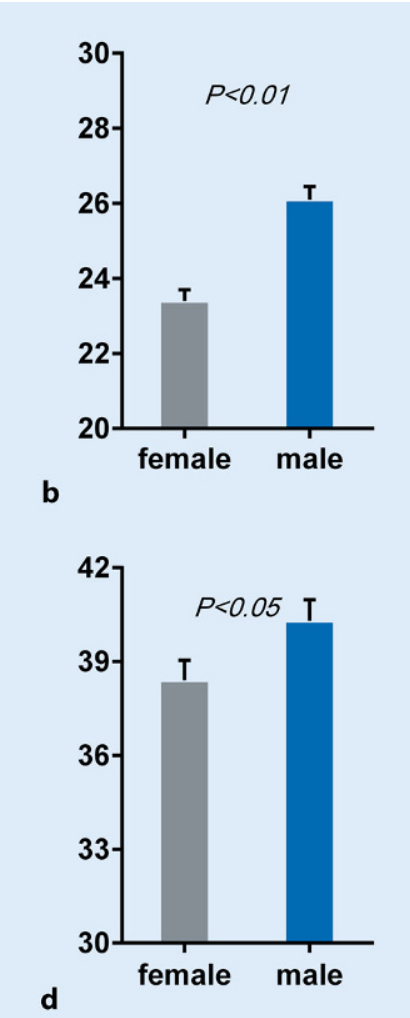

Fig. $1<$ Measurement (in $\mathrm{mm}$ ) of the annulus and ascending aorta: perimeter (a) and mean diameter of annulus (b); maximum diameter of ascending aorta (c) and ascending aorta diameter $4 \mathrm{~cm}$ above the annulus (d)
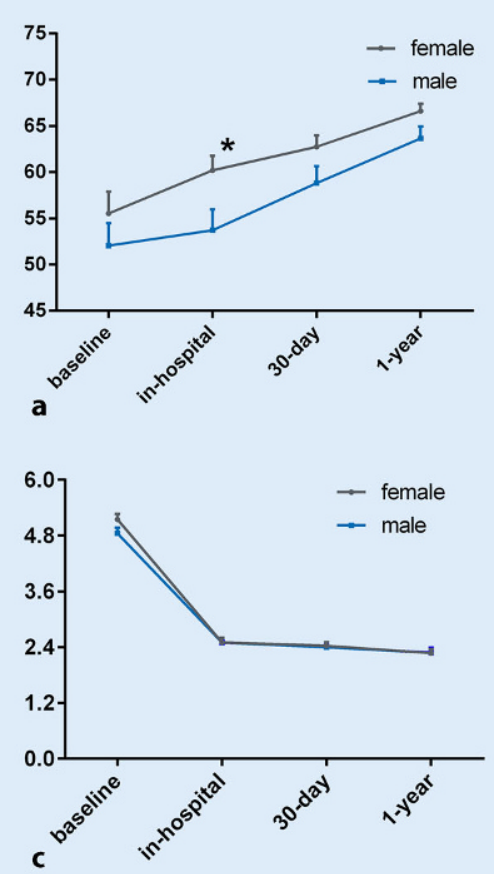

d
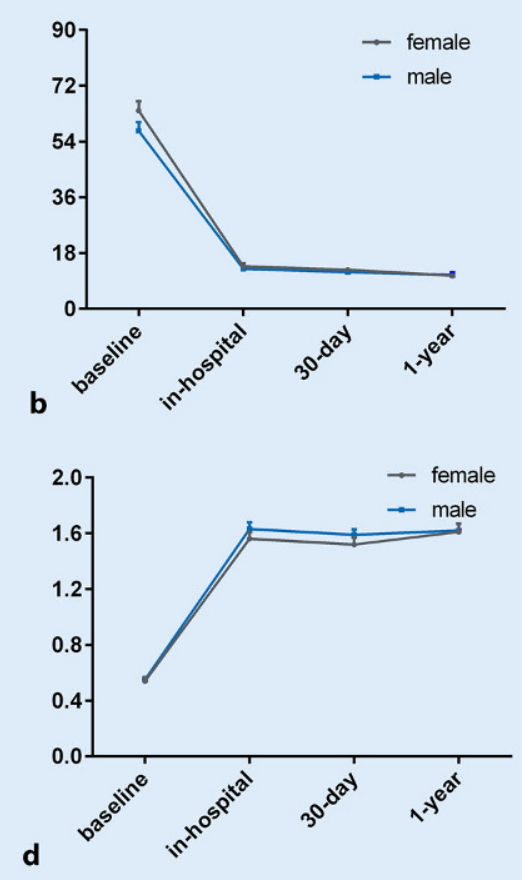

Fig. $2 \Delta$ Echocardiographic data. a Left ventricular ejection fraction (LVEF, \%), b mean gradient $(\mathrm{mmHg}), \mathrm{c}$ maximum velocity $(\mathrm{m} / \mathrm{s})$ and $\mathbf{d}$ aortic valve area $\left(\mathrm{cm}^{2}\right)$ across the aortic valve at baseline, in-hospital, 30-day and 1-year follow-up. . $p<0.05$ relatively smaller parameters of the aortic annulus including maximum diameter, minimum diameter, mean diameter, area, perimeter, area-derived diameter, perimeter-derived diameter, and the STJ average diameter through the generalized liner model. On the other hand, there were no significant sex differences in the STJ height, coronary ostia height, maximum diameter of aorta, ascending aorta diameter $(4 \mathrm{~cm})$, and aortic root angle (- Table 2).

\section{In-hospital complications}

According to VARC-2 criteria, there were no differences in perioperative complications between women and men, such as coronary obstruction, life-threatening bleeding, acute kidney injury, new pacemaker implantation and major vascular complication, which are shown in Supplement Table 1. All-cause mortality, moderate to severe paravalvular leakage, stroke and new pacemaker implantation rate at 30-day and 1-year showed no significant differences in the two groups (- Table 3).

\section{Discussion}

In order to identify sex differences in the aortic root complex and aorta in patients with BAV undergoing TAVR, we carefully studied and evaluated the anatomy of the aortic root and ascending aorta among patients with a BAV. After adjustment for the BSA, we found that women presented with smaller annulus dimensions such as annulus area, perimeter and diameter, and STJ diameter. However, there were no sex differences in the height of the STJ and coronary ostia, the dimensions of ascending aorta and aortic root angle. Postoperative complications and allcause mortality at 30-day and 1-year were similar between women and men. Previous studies have also demonstrated that the annulus, STJ and sinus of Valsalva dimensions and coronary ostia height in patients with a tricuspid aortic valve are larger in men compared with women, whereas dimensions of the ascending aorta are of similar magnitude $[14,16]$.

$\mathrm{BAV}$ disease is the common congenital heart defect. The reported frequency 


\begin{tabular}{|c|c|c|c|c|}
\hline Outcomes & Total & Female & Male & $p$ value \\
\hline \multicolumn{5}{|l|}{ In-hospital $(n=73)$} \\
\hline Mortality & $3(4.1 \%)$ & $2(5.4 \%)$ & $1(2.8 \%)$ & 1.00 \\
\hline$\geq$ Moderate PVL & $7(10.0 \%)$ & $2(5.6 \%)$ & $5(14.7 \%)$ & 0.38 \\
\hline \multicolumn{5}{|l|}{ Stroke } \\
\hline Disabling stroke & $0(0 \%)$ & $0(0 \%)$ & $0(0 \%)$ & - \\
\hline Nondisabling stroke & $4(5.5 \%)$ & $3(8.1 \%)$ & $1(2.8 \%)$ & 0.63 \\
\hline New pacemaker implantation & $6(8.3 \%)$ & $4(10.8 \%)$ & $2(5.7 \%)$ & 0.72 \\
\hline \multicolumn{5}{|l|}{30 Day $(n=73)$} \\
\hline Mortality & $3(4.1 \%)$ & $2(5.4 \%)$ & $1(2.8 \%)$ & 1.00 \\
\hline$\geq$ Moderate PVL & $3(4.6 \%)$ & $1(3.1 \%)$ & $2(6.1 \%)$ & 1.00 \\
\hline \multicolumn{5}{|l|}{ Stroke } \\
\hline Disabling stroke & $0(0 \%)$ & $0(0 \%)$ & $0(0 \%)$ & - \\
\hline Nondisabling stroke & $5(6.8 \%)$ & $4(10.8 \%)$ & $1(2.8 \%)$ & 0.37 \\
\hline New pacemaker implantation & $7(9.6 \%)$ & $4(10.8 \%)$ & $3(8.3 \%)$ & 1.00 \\
\hline \multicolumn{5}{|l|}{1 Year $(n=60)$} \\
\hline Mortality & $6(10.0 \%)$ & $3(9.4 \%)$ & $3(10.7 \%)$ & 1.00 \\
\hline$\geq$ Moderate PVL & $5(9.6 \%)$ & $1(3.4 \%)$ & $4(17.4 \%)$ & 0.22 \\
\hline \multicolumn{5}{|l|}{ Stroke } \\
\hline Disabling stroke & $0(0 \%)$ & $0(0 \%)$ & $0(0 \%)$ & - \\
\hline Nondisabling stroke & $6(10.0 \%)$ & $5(15.6 \%)$ & $1(3.6 \%)$ & 0.26 \\
\hline New pacemaker implantation & $7(11.7 \%)$ & $4(12.5 \%)$ & $3(10.7 \%)$ & 1.00 \\
\hline \multicolumn{5}{|c|}{$P V L$ paravalvular leakage, TAVR transcatheter aortic valve replacement } \\
\hline
\end{tabular}

of BAV in western TAVR registries ranges from $1.6 \%$ to $6.7 \%[18,19]$, which was much lower compared with those observed in the first TAVR trial in China (47.5\%) [3]. BAV has been considered as a relative contraindication because of the high procedural risk related to annulus eccentricity, asymmetrical valve calcification, unequally sized leaflets, and concomitant aortopathy [4]. However, TAVR in symptomatic bicuspid AS was associated with similar procedural complications and prognosis compared with tricuspid AS with the new-generation devices [6].

In our study, women have a smaller annulus. As expected, a smaller aortic annulus is associated with the use of a smaller prosthesis valve. We defined diameter $\leq 23 \mathrm{~mm}$ as small prosthesis valve, and $>23 \mathrm{~mm}$ as the common prosthesis valve. The proportion of small prosthesis valve used in women was much higher compared with men $(\leq 23 \mathrm{~mm} 18.9 \%$ vs. $0 \%$; $>23 \mathrm{~mm} 81.1 \%$ vs. $100 \%, p=0.01$ ), which is displayed in Supplementary Table 1. A previous study demonstrated that female sex is associated with a smaller of coronary artery after adjustment for BSA in the two groups. Ribeiro et al. discovered that patients with coronary obstruction exhibited a smaller aortic annulus area, sinus of Valsalva (SOV) diameter and STJ diameter, as well as left coronary height. The majority of patients with coronary obstruction were female patients. They also demonstrated that most patients with coronary obstruction had both a left coronary artery (LCA) height $<12 \mathrm{~mm}$ and a SOV diameter $<30 \mathrm{~mm} \mathrm{[10].} \mathrm{In} \mathrm{our} \mathrm{study,} \mathrm{the} \mathrm{mean}$ coronary height of the left main coronary artery (LM) and right coronary artery (RCA) were both greater than $12 \mathrm{~mm}$.

The aortic root angle and aortic valve calcification degree did not differ significantly between women and men in our study. By assessing the calcium volume with CT showed that Chinese people have a threefold excess of leaflet calcium burden compared with western patients, with a leaflet calcium volume of $421 \mathrm{~mm}$ versus $142 \mathrm{~mm}$ [3]. We also discovered that patients with BAV in our study have severe valve calcification. The proportion of women with moderate and above aortic valve calcification was $91.8 \%$, and $97.2 \%$ in men. Recent study data of the pathological morphology suggested that women may have relatively more valvular fibrosis compared with men. Besides aortic valve calcification, fibrosis indeed contributes to the development of valvular stenosis, and as opposed to aortic valve calcification, fibrosis is not detected by CT [23]. It is unknown whether patients with BAV have more valvular fibrosis, which would require valve biopsy for confirmation.

We found that women have better left ventricular ejection fraction (LVEF) than men after TAVR in the hospital $(60.2 \pm 9.7 \%$ vs. $53.7 \pm 13.6 \%, p=0.01)$, as shown in Supplement Table 1. But there was no difference in LVEF at 30days and 1 year between the two groups (• Fig. 2). This phenomenon is associated with myocardial response to severe AS. Myocardial remodeling occurs in response to increased left ventricular (LV) afterload and reverse remodeling following correction of severe AS by TAVR or surgery is different in women versus men. Women with severe AS typically mani- 
fested more concentric LV geometry, less myocardial fibrosis, and better systolic function compared with men [24, 25]. Surgical studies of patients undergoing aortic valve replacement (AVR) demonstrate less fibrosis on surgical biopsy of myocardium in women, and regression of myocardial hypertrophy is also more rapid in women [26]. Stangl et al. showed that following TAVR, although regression of hypertrophy occurred in men and women, improvement of ejection fraction was significant only in women, thus, potentially reflecting a lower burden of irreversible myocardial damage before TAVR [27]. There is no statistical difference in baseline LVEF between women and men in our study; however, the LVEF of female patients is significantly higher than that of men after TAVR, reflecting better improvement of LVEF in women. The correlation between myocardial remodeling and AS reflects the sex differences in the pathophysiology of myocardial response to the hemodynamic change of AS.

\section{Study limitation}

Limitations should be acknowledged. Our study is a retrospective and single-center study with a small sample. Statistical error in the analysis may be due to the small sample size. Whether the difference of the BAV structure is related to its pathological morphology is unknown.

\section{Conclusion}

Women with BAV have a smaller annulus and STJ diameter, even after indexing for BSA, and thus smaller valve prostheses tend to be selected in clinical practice. There are no differences in all-cause mortality at the 30-day and 1-year follow-up.

\section{Corresponding address}

\section{J. Wang}

Department of Cardiology, Second Affiliated

Hospital, Zhejiang University School of

Medicine

310009 Hangzhou, Zhejiang, China

wangjianan111@zju.edu.cn
Funding. This work was supported by Zhejiang Provincial Science and Technology Department Major Scientific and Technological Projects of major social programs (2015C03028).

\section{Compliance with ethical guidelines}

Conflict of interest. F. Du, X. Liu, Q. Zhu, Y. He, J. Jiang, T. Napawan, S. Jaiswal, Z. Chen and J. Wang declare that they have no competing interests.

This article depicts a retrospective study which does not interfere with therapy.

Open Access This article is distributed under the terms of the Creative Commons Attribution 4.0 International License (http://creativecommons.org/licenses/by/ 4.0/), which permits unrestricted use, distribution, and reproduction in any medium, provided you give appropriate credit to the original author(s) and the source, provide a link to the Creative Commons license, and indicate if changes were made.

\section{References}

1. Nishimura RA, Otto CM, Bonow RO etal (2017) 2017 AHA/ACC focused update of the 2014 AHA/ACC guideline for the management of patients with valvular heart disease: a report of the American College of Cardiology/American Heart Association Task Force on clinical practice guidelines. J Am Coll Cardiol 70(2):252-289

2. Siu SC, Silversides CK (2010) Bicuspid aortic valve disease. J Am Coll Cardiol 55(25):2789-2800

3. JilaihawiH, Wu Y, Yang Yet al (2015) Morphological characteristics of severe aortic stenosis in China: imaging corelab observations from the first Chinese transcatheter aortic valve trial. Catheter Cardiovasc Interv85(Suppl 1):752-761

4. Vahanian A, Alfieri O, Andreotti F et al (2012) Guidelines on the management of valvular heart disease (version 2012). Eur Heart J 33(19):2451-2496

5. Mylotte $D$, Lefevre $T$, Sondergaard $L$ et al (2014) Transcatheter aortic valve replacement in bicuspid aortic valve disease. J Am Coll Cardiol 64(22):2330-2339

6. Yoon SH, Bleiziffer S, De Backer O et al (2017) Outcomes in transcatheter aortic valve replacement for bicuspid versus tricuspid aortic valve stenosis. J Am Coll Cardiol 69(21):2579-2589

7. Sannino A, Cedars A, Stoler RC et al (2017) Comparison of efficacy and safety of transcatheter aortic valve implantation in patients with bicuspid versus tricuspid aortic valves. Am J Cardiol 120(9):1601-1606

8. Kodali SK, Williams MR, Smith CR et al (2012) Two-year outcomes after transcatheter or surgical aortic-valve replacement. N Engl J Med 366(18):1686-1695

9. Barbanti M, Yang TH, Rodes Cabau J et al (2013) Anatomical and procedural features associated with aortic root rupture during balloon-expandable transcatheter aortic valve replacement. Circulation 128(3):244-253

10. Ribeiro HB, Webb JG, Makkar RR et al (2013) Predictive factors, management, and clinical outcomes of coronary obstruction following transcatheter aortic valve implantation: insights from a large multicenter registry. J Am Coll Cardiol 62(17):1552-1562

11. Nazif TM, Dizon JM, Hahn RT et al (2015) Predictors and clinical outcomes of permanent pacemaker implantation after transcatheter aortic valve replacement: the PARTNER (Placement of AoRtic TraNscathetER Valves) trial and registry. JACC Cardiovasc Interv 8(1 PtA):60-69

12. Schultz CJ, Moelker AD, Tzikas A et al (2010) Cardiac CT: necessary for precise sizing for transcatheter aortic implantation. Eurolntervention 6(Suppl G):G6-G13

13. Achenbach S, Delgado V, Hausleiter J et al (2012) SCCT expert consensus document on computed tomography imaging before transcatheter aortic valve implantation (TAVI)/transcatheter aortic valve replacement (TAVR). J Cardiovasc Comput Tomogr 6(6):366-380

14. Buellesfeld L, Stortecky S, Kalesan B et al (2013) Aortic root dimensions among patients with severe aortic stenosis undergoing transcatheter aortic valve replacement. JACC Cardiovasc Interv 6(1):72-83

15. Naoum C, Blanke P, Dvir D et al (2016) Clinical outcomes and imaging findings in women undergoing TAVR. JACC Cardiovasc Imaging 9(4):483-493

16. Hamdan A, Barbash I, Schwammenthal E et al (2017) Sex differences in aortic root and vascular anatomy in patients undergoing transcatheter aortic valve implantation: a computed-tomographic study. J Cardiovasc Comput Tomogr 11 (2):87-96

17. Kappetein AP, Head SJ, Genereux P et al (2012) Updated standardized endpoint definitions for transcatheter aortic valve implantation: the Valve Academic Research Consortium-2 consensus document. J Am Coll Cardiol 60(15):1438-1454

18. Mack MJ, Brennan JM, Brindis R et al (2013) Outcomes following transcatheter aortic valve replacement in the United States. JAMA 310(19):2069-2077

19. Yoon SH, Ahn JM, Hayashida K et al (2016) Clinical outcomes following transcatheter aortic valve replacement in asian population. JACC CardiovasC Interv 9(9):926-933

20. O'Connor SA, Morice MC, Gilard M et al (2015) Revisiting sex equality with transcatheter aortic valve replacement outcomes: a collaborative, patient-level meta-analysis of 11,310 patients. JAm Coll Cardiol 66(3):221-228

21. Pan W, Zhou D, Pan C, Ge J (2012) Aortic valve annulus diameter in Chinese patients with severe calcific aortic valve stenosis: implications for transcatheter aortic valve implantation. Catheter Cardiovasc Interv 79(5):720-725

22. Michelena HI, Khanna AD, Mahoney Det al (2011) Incidence of aortic complications in patients with bicuspid aortic valves. JAMA 306(10):1104-1112

23. Simard L, DagenaisF, PibarotPetal (2015) Impact of sexon aortic valve calcification andfibrosis in aortic stenosis. Can J Cardiol 31 (10, Suppl):S312-S313

24. Douglas PS, Otto CM, Mickel MC et al (1995) Gender differences in left ventricle geometry and function in patients undergoing balloon dilatation of the aortic valve for isolated aortic stenosis. NHLBI Balloon Valvuloplasty Registry. Br Heart J 73(6):548-554

25. Kararigas G, Dworatzek E, Petrov G et al (2014) Sexdependent regulation of fibrosis and inflammation in human left ventricular remodelling under pressure overload. Eur JHeartFail 16(11):1160-1167

26. Petrov G, Regitz-Zagrosek V, Lehmkuhl E et al (2010) Regression of myocardial hypertrophy 
after aortic valve replacement: faster in women? Circulation 122(11 Suppl):S23-S28

27. Stangl V, Baldenhofer G, Knebel F et al (2012)

Impact of gender on three-month outcome and left ventricular remodeling after transfemoral

transcatheter aortic valve implantation. Am J Cardiol 110(6):884-890

Hier steht eine Anzeige.

\section{Springer}

